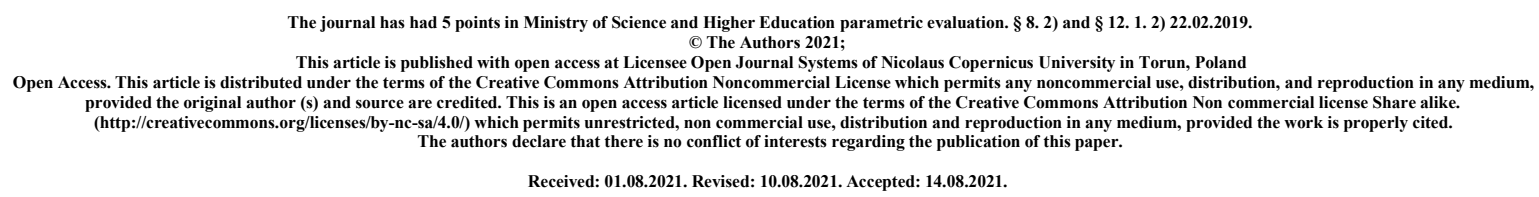

\title{
Chronic traumatic encephalopathy - current state of knowledge
}

\section{Lukasz Bryliński ${ }^{1}$, Paulina Drożak ${ }^{1}$, Martyna Drożak ${ }^{1}$, Katarzyna Augustowska ${ }^{1}$, Piotr Duda ${ }^{1}$, Agata Bura ${ }^{1}$, Ewa Rudnicka-Drożak ${ }^{2}$}

1. Students' Scientific Association of Chair and Department of Family Medicine, Medical University of Lublin.

2. Chair and Department of Family Medicine, Medical University of Lublin.

\begin{abstract}
Introduction and purpose. Chronic traumatic encephalopathy (CTE) is a tauopathy caused by repetitive, mild head injuries. It is characterized by perivascular accumulation of hyperphosphorylated tau protein in the neurons and astrocytes. CTE leads to changes in central nervous system, both on microscopic and macroscopic level. The aim of the study was to present the current knowledge on chronic traumatic encephalopathy among athletes, its predisposing factors, symptoms and consequences, as well as diagnostic methods and treatment.
\end{abstract}

Description. CTE occurs among contact sport players, such as American football, ice hockey, soccer, baseball, box and MMA (mixed martial arts), as well as among soldiers and victims of domestic violence. Repetitive head injuries and long career duration increase the risk of CTE. Symptoms of chronic traumatic encephalopathy include a commonly occurring triad: cognitive disturbances, behavioral problems and mood disturbances. Other symptoms include memory loss, parkinsonism, headaches, speech and walking problems. Currently, the only 
diagnostic method of CTE is a posthumous detection of neuropathological markers. Methods such as detection of exosomal tau protein in plasma and imaging techniques give hope to diagnose CTE in alive patients. Treatment methods of CTE, such as LIPUS (low intensity pulsed ultrasound) therapy are currently being developed.

Conclusions. Chronic traumatic encephalopathy among athletes is a serious problem that affects multiple people due to the popularity of contact sports. Thus, an emphasis should be put on prevention, raising awareness and appropriate protection of athletes through changes in regulations and improvement of protective equipment.

\section{Key words: chronic traumatic encephalopathy; athletes}

\section{Introduction and purpose}

Chronic traumatic encephalopathy (CTE) is a neuropathological disease associated with changes that occur as a result of mild, repetitive brain injuries [1]. CTE was first described in 1928 by Harrison Stanford Martland, a pathologist from Newark, New Jersey. In his article, Martland described cases of 23 boxers and introduced a term "punch drunk" into medical terminology which was used to describe experienced boxers who had a tendency to instability, slower movement, slower thinking, confusion and trembling $[2,3]$. The exact term of „chronic traumatic encephalopathy" was firstly introduced in 1949 by doctor Macdonald Critchley [4]. A pathognomonic trait that accompanies CTE and allows to differentiate it from other neurodegenerative diseases consists of perivascular accumulation of hyperphosphorylated tau protein in neurons and astrocytes. CTE leads to changes in central nervous system, both on microscopic and macroscopic level. In case of mild CTE, only subtle changes are visible, such as changes in lateral ventricles and third ventricle and occasionally also pallor of the locus coeruleus and substantia nigra. In more advanced cases one can notice a decrease in brain mass, frontal and temporal atrophy with significant atrophy of medial temporal part with compensatory expansion of lateral ventricles and third ventricle. There also occurs an atrophy of the thalamus, hypothalamus and mamillary body, as well as thinning of the corpus callosum and reduction of the subcortical white matter. A cavity or a fenestration in the septum pellucidum is also common [5]. It is important to remember that the brain might be seemingly unchanged on the macroscopic level. Whereas in the microscopic changes one can include intracellular aggregates of the phosphorylated tau protein, axonal damage and, in 
advanced cases, loss of neurons and precipitation of DNA binding protein TAR 43 (TDP-43) in neurons and glial cells. The perivascular accumulation of hyperphosphorylated tau protein in neurons and astrocytes is considered a pathognomonic trait of CTE [6]. The prevalence of CTE among professional boxers is estimated to be around $17 \%$, whereas at least $3.7 \%$ of NFL (National Football League) players will develop CTE during their lifetime [7]. The typical age at the onset of symptoms is between 30 and 65 years, although evidence for CTE was found as early as in 14 year old American high schoolers who played American football [5]. 4 stages of CTE are distinguished; from the first one, where only microscopic changes are visible, there is a gradual proceeding of microscopic and macroscopic pathological changes, up to the fourth stage, where the brain mass significantly decreases which is caused by atrophy. Atrophic brains often reach a mass of under 1000 grams [8].

Chronic traumatic encephalopathy may also co-occur with other diseases of central nervous system, such as: Lewy body dementia, which was diagnosed in $17 \%$ of patients with CTE; motor neuron disease, which developed in about $11 \%$ of patients with CTE; Alzheimer disease which was diagnosed in $12 \%$ of patients with CTE (there is also evidence for head injury to be a risk factor for Alzheimer disease) and frontotemporal degeneration, which was found in $6 \%$ of patients with CTE. It was also found that alpha-synuclein accumulates in the axons after traumatic brain injury and it is suggested that its accumulation might synergistically influence the aggregation of the tau protein [9].

The aim of the study was to present the current knowledge on chronic traumatic encephalopathy among athletes, its predisposing factors, symptoms and consequences, as well as on the diagnostic methods and treatment.

\section{Predisposing factors}

Chronic traumatic encephalopathy is found in contact sport players. One of the groups at risk of CTE are American football players. A research conducted among 202 deceased former American football players through a retrospective clinical study and neuropathological evaluation showed that $87 \%(n=177)$ of them obtained a positive diagnosis of CTE [10]. Others sports that increase the risk of the occurrence of CTE are: ice hockey, soccer, baseball, rugby, box, wrestling and MMA (Mixed Martial Arts) [11,12]. What is interesting, in a group of American high school students, ice hockey and lacrosse are considered to be the sports that carry the highest risk for development of CTE among boys, whereas among girls soccer, 
lacrosse and volleyball are the most risky [13]. The all above-mentioned groups of sports players have in common an exposure to mild, repetitive head injuries which are the main risk factor for CTE [14]. The other important risk factor is long career duration. A research carried out on brains of 266 deceased American football players showed a positive correlation between duration of the sports career and risk of CTE - the risk increases by $30 \%$ with every year of playing, doubles every 2.6 years and increases 10 times every 9 years. Additionally, among the participants of the study a relationship was found between longer duration of career and the occurrence of severe CTE; each year of playing was increasing the risk of the occurrence of severe CTE at the moment of death by 14\% [15]. Another risk factor for CTE was genetic predisposition. An example of this is the presence of isoforms of the ApoE protein. The ApoE gene is located on the chromosome 19 and is polymorphic. The products of this gene are endogenous immunomodulators which are synthesized in response to injury. Contrary to the isoforms $A P O E \varepsilon 2$ and $A P O E \varepsilon 3, A P O E-\varepsilon 4$ due to its structure doesn't have a capacity to detoxify cytotoxic products of lipid peroxidation. The isoform $A P O E-\varepsilon 4$ is proven to have an influence on the development of Alzheimer disease and is considered to have an influence on CTE; however, this issue requires further research [16]. Research is also being conducted on the influence of genetic variants MAPT and TMEM106B [17]. It is also worth noting that not only athletes are a group at risk of CTE, but also professional soldiers and veterans which is caused by exposure to an explosion of improvised explosive devices $[18,19]$. Another group at risk for CTE are women exposed to domestic violence. The term „battered woman syndrome" was firstly described by JJ Gayford in 1975 [20].

\section{Symptoms and consequences of CTE}

Symptoms of chronic traumatic encephalopathy include a commonly occurring triad: cognitive disturbances, behavioral problems and mood disturbances. The presence of two different types of CTE is suggested. The first one is characterized by the onset at younger age, behavioral and mood disturbances, but minimal cognitive and motor disturbances. The second one is distinguished by the onset at older age, but bigger impairment of cognitive functions, often with motor disturbances [21]. 3 stages of deterioration of clinical state have been described. The first stage is characterized by affective disturbances and psychotic symptoms.

During the second stage, antisocial behavior, memory loss and initial symptoms of Parkinson's disease occur. In the third stage of CTE a patient has overall cognitive 
disturbances that lead to dementia. Development of full-blown parkinsonism, speech and walking impairment are also possible [22]. During CTE, a patient may have behavioral problems, such as impulsiveness and loss of self-control. Other symptoms include memory deficit and impairment of attention. About $45 \%$ of patients with CTE develop dementia, $66 \%$ of them over the age of 60 have dementia. Chronic headaches are present in 30\% of people with CTE. Motor disturbances also develop, including dysartria (speech disturbance characterized by poor articulation), dysphagia (difficulty in swallowing), coordination problems and symptoms of parkinsonism, such as trembling and mask face. CTE also increases a chance of the occurrence of anxiety and depression [4,23,24,25]. Taking into account a hazard of suicide, research is not consistent and requires further investigation. What is interesting, a research concerning former NFL players showed that suicide ratio in this group is lower than ratio in general population of men. It also seems that causes of suicide are complex and multifactorial, so it is difficult to assess whether patients with CTE have an increased risk of committing suicide [26,27].

\section{Diagnostics, prevention and treatment}

Currently, the only method of diagnosing CTE is through a posthumous detection of presence of neuropathological changes and markers in the brain. Clinical criteria are being developed based on retrospective studies, such as speaking with the relatives of a deceased patient. In order to diagnose CTE earlier and implement potential treatment, there is a need to define non-invasive biomarkers of CTE in vivo [28,29]. Detection of ${ }^{8}$ F-flortaucipir (FTP) in positron emission tomography (PET) is one of the potentially useful methods of diagnosing CTE. The use of flortaucipir is practical in another neurodegenerative disease - Alzheimer's disease, where it may serve as a tool that helps in diagnosis, in order to evaluate stage of the disease and to monitor effects of the therapy. In chronic traumatic encephalopathy, binding of FTP in temporal and frontal lobes corresponds with the presence of changes and illustrates distribution of pathological changes in later stages of CTE (stage III and IV). However, the intensity of signal seems to be significantly smaller than in the case of Alzheimer's disease. Also the method itself seems to be ineffective in detecting pathological changes in early stages of the disease which shows that FTP-PET may have limited usefulness in the diagnostic process of CTE $[31,32,33]$. Another imaging method potentially useful in the diagnostics of CTE is magnetic resonance imaging (MRI) which detects characteristic 
changes, such as cavum septum pellucidum. Another potentially useful method in the diagnostics of CTE is diffusion tensor imaging (DTI). To sum up, the development of imaging techniques gives hope to use them in the future in order to diagnose CTE which would enable to implement proper preventive strategies for CTE [33]. Another non-invasive method that could be potentially useful in the diagnostics of CTE is detection of exosomal tau protein in the blood plasma. Exosomes are a type of vesicles freed into the extracellular space by all cells in the body, including brain cells. Their content directly reflects the content of the cell from which they are derived. Measurement of the exosomal tau protein seems to be a promising marker of CTE which may serve in the future as a screening test. A research carried out among former NFL players, who are exposed to CTE, showed increased levels of this protein [34].

The issue of treatment of CTE, as well as diagnostics in alive patients, still remains in the sphere of research. However, there are several interesting therapeutic propositions. One of the ideas is the use of the LIPUS therapy - low intensity pulsed ultrasound - in order to prevent the consequences of head injuries which lead to CTE. The application of this method seems to be helpful, because it stimulates the production of growth factors, including BDNF which decreases the expression of tau protein. The LIPUS therapy also holds back the neuroinflammatory process which takes part in the pathogenesis of CTE. Apart from that, the above-mentioned therapy also decreases the cerebral edema. There is also pre-clinical evidence which suggests that LIPUS therapy improves cognitive function and has antidepressant properties. The therapy itself may find its use in the future in prevention strategy of CTE [35]. In TBI (traumatic brain injury), which increases the risk of CTE, there is a correlation between presence of the cis-tau protein in the cortical axons, as well as in cerebrospinal fluid, and axonal damage and also clinical state of the patient. This creates a possibility of using the antibodies against cis P-tau in detecting cerebral changes, as well as in the treatment of CTE. Research conducted on laboratory animals showed that those antibodies could hold back the subsequent production of the tau protein and atrophy of the brain, as well as prevent the neurodegeneration after an injury and hence hold back the development of CTE $[36,37]$.

Also it is considered to use viruses as vectors that carry a gene for monoclonal antibody aimed against the tau protein. Expression of the gene should provide a sufficient level of 
antibodies that would prevent its accumulation. A research conducted on mice showed that delivery of AAVrh.10 expression vectors that encoded an antibody against tau protein to the hippocampus resulted in a significant decrease of the tau protein in central nervous system [38]. It is considered that inflammatory process plays an important role in the pathogenesis of CTE. The chemokine CCL2 is an important mediator of the above-mentioned process, because it is responsible for the recruitment of the macrophages and microglia in the place of injury as a result of concussion or a hit. That is why CCL2 may be a target in future therapies in order to decrease an inflammation in the nervous system [39]. Research carried out on mice suggests that docosahexaenoic acid (DHA), due to its capacity to inhibit the tau protein kinase, has a pharmacotherapeutic potential as a preventive measure for the development of CTE. DHA is also a promising treatment agent for CTE [40]. The inhibition of monoacylglycerol lipase (MAGL) in the mice model resulted in a decrease of neuropathological changes similar to CTE which suggests that MAGL may be the target of the therapy in the future [41].

Currently, due to lack of possibilities of treatment, the biggest role is attributed to prevention and early detection of symptoms [42]. It is necessary to educate society, especially parents of the young athletes. An access should be provided to educational materials on symptoms and potential preventive strategies of CTE. It is also crucial to raise awareness of the hazard among coaches of the young athletes [43]. It is equally important to raise awareness and knowledge about CTE among young players, because it gives them a possibility to make a conscious decision whether to continue to play the sport and informs them about a possible risk of developing neurodegenerative diseases. Alternative sports, such as swimming, tennis, basketball and volleyball should be promoted among teenagers, whereas boxing should be unrecommended for children or teenagers and proper healthcare should be provided for those who decide to practice this sport $[44,45]$. In order to decrease the risk of CTE in contact sports, changes in regulations are being made, such as limiting intentional body contact among players from younger age groups in ice hockey, elimination of hitting the opponent in the head with an upper limb in soccer as well as an introduction of more severe punishments for players who get a red card during a match and being banned from several next games for a deliberate attack for the head of an opponent. Among preventive measures, banning playing ball with the head in schools should be included. It is also important to educate young athletes, so they respect the rules of fair play and don't use potentially dangerous playing techniques [8, $46,47]$. In soccer it is crucial to use appropriate pads, select the equipment adjusted to the age of players and make sure that the size and inflation of the ball is proper, so that the frequency 
of head injuries is decreased. It is also considered to introduce suitable head protectors for players [48]. Whereas in American football it is suggested that the currently used helmets don't provide appropriate protection of the head - they prevent skull fracture, but they don't protect against head injuries. Designing helmets that protect against brain injuries requires collaboration between doctors and engineers. One of the solutions suggested in production of the new generation helmets is to use silicone inserts encased with a material that limits friction. This should prevent the hits from affecting the head due to silicon's properties of absorbing the energy of the hit and preventing the conduction of vibration. Despite of new construction, helmets would most probably remain their current appearance $[49,50]$.

\section{Summary}

Chronic traumatic encephalopathy among athletes is a serious problem that affects many people due to the popularity of contact sports. It is important to further explore this disease, its pathophysiological mechanism, course, predisposing factors and long-term effects. A development of diagnostic methods gives hope to diagnose CTE during lifetime. A search for new potential treatment methods is also promising. However, currently, due to lack of possibility of detection of CTE in alive patients and lack of treatment, an emphasis should be put on prevention, raising awareness and appropriate protection of the athletes through changes in regulations and improvement of protective equipment.

\section{Bibliography}

1. McKee AC, Stern RA, Nowinski CJ, Stein TD, Alvarez VE, Daneshvar DH, Lee HS, Wojtowicz SM, Hall G, Baugh CM, Riley DO, Kubilus CA, Cormier KA, Jacobs MA, Martin BR, Abraham CR, Ikezu T, Reichard RR, Wolozin BL, Budson AE, Goldstein LE, Kowall NW, Cantu RC. The spectrum of disease in chronic traumatic encephalopathy. Brain. 2013 Jan;136(Pt 1):43-64. doi: 10.1093/brain/aws307. Epub 2012 Dec 2. Erratum in: Brain. 2013 Oct;136(Pt 10):e255. PMID: 23208308; PMCID: PMC3624697.

2. Omalu BI, Bailes J, Hammers JL, Fitzsimmons RP. Chronic traumatic encephalopathy, suicides and parasuicides in professional American athletes: the role of the forensic 
pathologist. Am J Forensic Med Pathol. 2010 Jun;31(2):130-2. doi: 10.1097/PAF.0b013e3181ca7f35. PMID: 20032774.

3. Karantzoulis S, Randolph C. Modern chronic traumatic encephalopathy in retired athletes: what is the evidence? Neuropsychol Rev. 2013 Dec;23(4):350-60. doi: 10.1007/s11065013-9243-4. Epub 2013 Nov 22. PMID: 24264648.

4. McKee AC, Alosco ML, Huber BR. Repetitive Head Impacts and Chronic Traumatic Encephalopathy. Neurosurg Clin N Am. 2016 Oct;27(4):529-35. doi: 10.1016/j.nec.2016.05.009. PMID: 27637402; PMCID: PMC5028120.

5. Mez J, Stern RA, McKee AC. Chronic traumatic encephalopathy: where are we and where are we going? Curr Neurol Neurosci Rep. 2013 Dec;13(12):407. doi: 10.1007/s11910013-0407-7. PMID: 24136455; PMCID: PMC4550089.

6. Turner RC, Lucke-Wold BP, Robson MJ, Omalu BI, Petraglia AL, Bailes JE. Repetitive traumatic brain injury and development of chronic traumatic encephalopathy: a potential role for biomarkers in diagnosis, prognosis, and treatment? Front Neurol. 2013 Jan 17;3:186. doi: 10.3389/fneur.2012.00186. PMID: 23335911; PMCID: PMC3547169.

7. Love S, Solomon GS. Talking with parents of high school football players about chronic traumatic encephalopathy: a concise summary. Am J Sports Med. 2015 May;43(5):1260-4. doi: 10.1177/0363546514535187. Epub 2014 Jun 6. PMID: 24907288.

8. Nitrini R. Soccer (Football Association) and chronic traumatic encephalopathy: A short review and recommendation. Dement Neuropsychol. 2017 Jul-Sep;11(3):218-220. doi: 10.1590/1980-57642016dn11-030002. PMID: 29213517; PMCID: PMC5674664.

9. Stein TD, Alvarez VE, McKee AC. Chronic traumatic encephalopathy: a spectrum of neuropathological changes following repetitive brain trauma in athletes and military personnel. Alzheimers Res Ther. 2014 Jan 15;6(1):4. doi: 10.1186/alzrt234. PMID: 24423082; PMCID: PMC3979082.

10. Mez J, Daneshvar DH, Kiernan PT, Abdolmohammadi B, Alvarez VE, Huber BR, Alosco ML, Solomon TM, Nowinski CJ, McHale L, Cormier KA, Kubilus CA, Martin BM, 
Murphy L, Baugh CM, Montenigro PH, Chaisson CE, Tripodis Y, Kowall NW, Weuve J, McClean MD, Cantu RC, Goldstein LE, Katz DI, Stern RA, Stein TD, McKee AC. Clinicopathological Evaluation of Chronic Traumatic Encephalopathy in Players of American Football. JAMA. 2017 Jul 25;318(4):360-370. doi: 10.1001/jama.2017.8334. PMID: $28742910 ;$ PMCID: PMC5807097.

11. Mckee AC, Abdolmohammadi B, Stein TD. The neuropathology of chronic traumatic encephalopathy. Handb Clin Neurol. 2018;158:297-307. doi: 10.1016/B978-0-444-639547.00028-8. PMID: 30482357.

12. Lim LJH, Ho RCM, Ho CSH. Dangers of Mixed Martial Arts in the Development of Chronic Traumatic Encephalopathy. Int J Environ Res Public Health. 2019 Jan 17;16(2):254. doi: 10.3390/ijerph16020254. PMID: 30658408; PMCID: PMC6352039.

13. Hornbeck K, Walter K, Myrvik M. Should Potential Risk of Chronic Traumatic Encephalopathy Be Discussed with Young Athletes? AMA J Ethics. 2017 Jul 1;19(7):686-692. doi: 10.1001/journalofethics.2017.19.7.pfor1-1707. PMID: 28813241.

14. Stein TD, Alvarez VE, McKee AC. Concussion in Chronic Traumatic Encephalopathy. Curr Pain Headache Rep. 2015 Oct;19(10):47. doi: 10.1007/s11916-015-0522-z. PMID: 26260277; PMCID: PMC4633042.

15. Mez J, Daneshvar DH, Abdolmohammadi B, Chua AS, Alosco ML, Kiernan PT, Evers L, Marshall L, Martin BM, Palmisano JN, Nowinski CJ, Mahar I, Cherry JD, Alvarez VE, Dwyer B, Huber BR, Stein TD, Goldstein LE, Katz DI, Cantu RC, Au R, Kowall NW, Stern RA, McClean MD, Weuve J, Tripodis Y, McKee AC. Duration of American Football Play and Chronic Traumatic Encephalopathy. Ann Neurol. 2020 Jan;87(1):116131. doi: 10.1002/ana.25611. Epub 2019 Nov 23. PMID: 31589352; PMCID: PMC6973077.

16. Deng H, Ordaz A, Upadhyayula PS, Gillis-Buck EM, Suen CG, Melhado CG, Mohammed N, Lam T, Yue JK. Apolipoprotein E Epsilon 4 Genotype, Mild Traumatic Brain Injury, and the Development of Chronic Traumatic Encephalopathy. Med Sci (Basel). 2018 Sep 14;6(3):78. doi: 10.3390/medsci6030078. PMID: 30223506; PMCID: PMC6163513. 
17. Bieniek KF, Ross OA, Cormier KA, Walton RL, Soto-Ortolaza A, Johnston AE, DeSaro P, Boylan KB, Graff-Radford NR, Wszolek ZK, Rademakers R, Boeve BF, McKee AC, Dickson DW. Chronic traumatic encephalopathy pathology in a neurodegenerative disorders brain bank. Acta Neuropathol. 2015 Dec;130(6):877-89. doi: 10.1007/s00401015-1502-4. Epub 2015 Oct 30. PMID: 26518018; PMCID: PMC4655127.

18. Gandy S, Ikonomovic MD, Mitsis E, Elder G, Ahlers ST, Barth J, Stone JR, DeKosky ST. Chronic traumatic encephalopathy: clinical-biomarker correlations and current concepts in pathogenesis. Mol Neurodegener. 2014 Sep 17;9:37. doi: 10.1186/1750-1326-9-37. PMID: 25231386; PMCID: PMC4249716.

19. Goldstein LE, Fisher AM, Tagge CA, Zhang XL, Velisek L, Sullivan JA, Upreti C, Kracht JM, Ericsson M, Wojnarowicz MW, Goletiani CJ, Maglakelidze GM, Casey N, Moncaster JA, Minaeva O, Moir RD, Nowinski CJ, Stern RA, Cantu RC, Geiling J, Blusztajn JK, Wolozin BL, Ikezu T, Stein TD, Budson AE, Kowall NW, Chargin D, Sharon A, Saman S, Hall GF, Moss WC, Cleveland RO, Tanzi RE, Stanton PK, McKee AC. Chronic traumatic encephalopathy in blast-exposed military veterans and a blast neurotrauma mouse model. Sci Transl Med. 2012 May 16;4(134):134ra60. doi: 10.1126/scitranslmed.3003716. PMID: 22593173; PMCID: PMC3739428.

20. Casper ST, O'Donnell K. The punch-drunk boxer and the battered wife: Gender and brain injury research. Soc Sci Med. 2020 Jan;245:112688. doi: 10.1016/j.socscimed.2019.112688. Epub 2019 Nov 20. PMID: 31830739.

21. Stern RA, Daneshvar DH, Baugh CM, Seichepine DR, Montenigro PH, Riley DO, Fritts NG, Stamm JM, Robbins CA, McHale L, Simkin I, Stein TD, Alvarez VE, Goldstein LE, Budson AE, Kowall NW, Nowinski CJ, Cantu RC, McKee AC. Clinical presentation of chronic traumatic encephalopathy. Neurology. 2013 Sep 24;81(13):1122-9. doi: 10.1212/WNL.0b013e3182a55f7f. Epub 2013 Aug 21. PMID: 23966253; PMCID: PMC3795597.

22. Roberts GW, Allsop D, Bruton C. The occult aftermath of boxing. J Neurol Neurosurg Psychiatry. 1990 May;53(5):373-8. doi: 10.1136/jnnp.53.5.373. PMID: 2191084; PMCID: PMC488051. 
23. Manley G, Gardner AJ, Schneider KJ, Guskiewicz KM, Bailes J, Cantu RC, Castellani RJ, Turner M, Jordan BD, Randolph C, Dvořák J, Hayden KA, Tator CH, McCrory P, Iverson GL. A systematic review of potential long-term effects of sport-related concussion. Br J Sports Med. 2017 Jun;51(12):969-977. doi: 10.1136/bjsports-2017-097791. Epub 2017 Apr 28. PMID: 28455362; PMCID: PMC5466926.

24. Meehan W 3rd, Mannix R, Zafonte R, Pascual-Leone A. Chronic traumatic encephalopathy and athletes. Neurology. 2015 Oct 27;85(17):1504-11. doi: 10.1212/WNL.0000000000001893. Epub 2015 Aug 7. PMID: 26253448; PMCID: PMC4631072.

25. Stern RA, Riley DO, Daneshvar DH, Nowinski CJ, Cantu RC, McKee AC. Long-term consequences of repetitive brain trauma: chronic traumatic encephalopathy. PM R. 2011 Oct;3(10 Suppl 2):S460-7. doi: 10.1016/j.pmrj.2011.08.008. PMID: 22035690.

26. Webner D, Iverson GL. Suicide in professional American football players in the past 95 years. Brain Inj. 2016;30(13-14):1718-1721. doi: 10.1080/02699052.2016.1202451. Epub 2016 Oct 24. PMID: 27996330.

27. Iverson GL. Retired National Football League Players are Not at Greater Risk for Suicide. Arch Clin Neuropsychol. 2020 Apr 20;35(3):332-341. doi: 10.1093/arclin/acz023. PMID: 31665203; PMCID: PMC7297280.

28. Lin A, Charney M, Shenton ME, Koerte IK. Chronic traumatic encephalopathy: neuroimaging biomarkers. Handb Clin Neurol. 2018;158:309-322. doi: 10.1016/B978-0444-63954-7.00029-X. PMID: 30482359.

29. D'Ascanio S, Alosco ML, Stern RA. Chronic traumatic encephalopathy: clinical presentation and in vivo diagnosis. Handb Clin Neurol. 2018;158:281-296. doi: 10.1016/B978-0-444-63954-7.00027-6. PMID: 30482356.

30. Pontecorvo MJ, Devous MD Sr, Navitsky M, Lu M, Salloway S, Schaerf FW, Jennings D, Arora AK, McGeehan A, Lim NC, Xiong H, Joshi AD, Siderowf A, Mintun MA; 18FAV-1451-A05 investigators. Relationships between flortaucipir PET tau binding and 
amyloid burden, clinical diagnosis, age and cognition. Brain. 2017 Mar 1;140(3):748-763. doi: 10.1093/brain/aww334. PMID: 28077397; PMCID: PMC5382945.

31. Lesman-Segev OH, La Joie R, Stephens ML, Sonni I, Tsai R, Bourakova V, Visani AV, Edwards L, O'Neil JP, Baker SL, Gardner RC, Janabi M, Chaudhary K, Perry DC, Kramer JH, Miller BL, Jagust WJ, Rabinovici GD. Tau PET and multimodal brain imaging in patients at risk for chronic traumatic encephalopathy. Neuroimage Clin. 2019;24:102025. doi: 10.1016/j.nicl.2019.102025. Epub 2019 Oct 17. PMID: 31670152; PMCID: PMC6831941.

32. Mantyh WG, Spina S, Lee A, Iaccarino L, Soleimani-Meigooni D, Tsoy E, Mellinger TJ, Grant H, Vandevrede L, La Joie R, Lesman-Segev O, Gaus S, Possin KL, Grinberg LT, Miller BL, Seeley WW, Rabinovici GD. Tau Positron Emission Tomographic Findings in a Former US Football Player With Pathologically Confirmed Chronic Traumatic Encephalopathy. JAMA Neurol. 2020 Apr 1;77(4):517-521. doi: 10.1001/jamaneurol.2019.4509. PMID: 31904765; PMCID: PMC6990867.

33. Koerte IK, Lin AP, Willems A, Muehlmann M, Hufschmidt J, Coleman MJ, Green I, Liao H, Tate DF, Wilde EA, Pasternak O, Bouix S, Rathi Y, Bigler ED, Stern RA, Shenton ME. A review of neuroimaging findings in repetitive brain trauma. Brain Pathol. 2015 May;25(3):318-49. doi: 10.1111/bpa.12249. PMID: 25904047; PMCID: PMC5699448.

34. Stern RA, Tripodis Y, Baugh CM, Fritts NG, Martin BM, Chaisson C, Cantu RC, Joyce JA, Shah S, Ikezu T, Zhang J, Gercel-Taylor C, Taylor DD. Preliminary Study of Plasma Exosomal Tau as a Potential Biomarker for Chronic Traumatic Encephalopathy. J Alzheimers Dis. 2016;51(4):1099-109. doi: 10.3233/JAD-151028. PMID: 26890775; PMCID: PMC4833534.

35. Tsai SJ. Preventive potential of low intensity pulsed ultrasound for chronic traumatic encephalopathy after repetitive head collisions in contact sports. Med Hypotheses. 2020 Jan;134:109422. doi: 10.1016/j.mehy.2019.109422. Epub 2019 Oct 10. PMID: 31654885.

36. VanItallie TB. Traumatic brain injury (TBI) in collision sports: Possible mechanisms of transformation into chronic traumatic encephalopathy (CTE). Metabolism. 2019 Nov;100S:153943. doi: 10.1016/j.metabol.2019.07.007. PMID: 31610856. 
37. Kondo A, Shahpasand K, Mannix R, Qiu J, Moncaster J, Chen CH, Yao Y, Lin YM, Driver JA, Sun Y, Wei S, Luo ML, Albayram O, Huang P, Rotenberg A, Ryo A, Goldstein LE, Pascual-Leone A, McKee AC, Meehan W, Zhou XZ, Lu KP. Antibody against early driver of neurodegeneration cis P-tau blocks brain injury and tauopathy. Nature. 2015 Jul 23;523(7561):431-436. doi: 10.1038/nature14658. Epub 2015 Jul 15. PMID: 26176913; PMCID: PMC4718588.

38. Sacramento CB, Sondhi D, Rosenberg JB, Chen A, Giordano S, Pey E, Lee V, Stiles KM, Havlicek DF, Leopold PL, Kaminsky SM, Crystal RG. Anti-Phospho-Tau Gene Therapy for Chronic Traumatic Encephalopathy. Hum Gene Ther. 2020 Jan;31(1-2):57-69. doi: 10.1089/hum.2019.174. Epub 2019 Dec 13. PMID: 31608704.

39. Cherry JD, Meng G, Daley S, Xia W, Svirsky S, Alvarez VE, Nicks R, Pothast M, Kelley H, Huber B, Tripodis Y, Alosco ML, Mez J, McKee AC, Stein TD. CCL2 is associated with microglia and macrophage recruitment in chronic traumatic encephalopathy. $\mathrm{J}$ Neuroinflammation. 2020 Dec 5;17(1):370. doi: 10.1186/s12974-020-02036-4. PMID: 33278887; PMCID: PMC7718711.

40. Lucke-Wold BP, Turner RC, Logsdon AF, Nguyen L, Bailes JE, Lee JM, Robson MJ, Omalu BI, Huber JD, Rosen CL. Endoplasmic reticulum stress implicated in chronic traumatic encephalopathy. J Neurosurg. 2016 Mar;124(3):687-702. doi: 10.3171/2015.3.JNS141802. Epub 2015 Sep 18. PMID: 26381255.

41. Zhang J, Teng Z, Song Y, Hu M, Chen C. Inhibition of monoacylglycerol lipase prevents chronic traumatic encephalopathy-like neuropathology in a mouse model of repetitive mild closed head injury. J Cereb Blood Flow Metab. 2015 Mar;35(3):443-53. doi: 10.1038/jcbfm.2014.216. Epub 2014 Dec 10. Erratum in: J Cereb Blood Flow Metab. 2015 Apr;35(4):706. PMID: 25492114; PMCID: PMC4348384.

42. Martínez-Pérez R, Paredes I, Munarriz PM, Paredes B, Alén JF. Chronic traumatic encephalopathy: The unknown disease. Neurologia. 2017 Apr;32(3):185-191. English, Spanish. doi: 10.1016/j.nrl.2014.08.009. Epub 2014 Dec 17. PMID: 25534950. 
43. Daugherty J, Sarmiento K. Chronic traumatic encephalopathy: what do parents of youth athletes know about it? Brain Inj. 2018;32(13-14):1773-1779. doi: 10.1080/02699052.2018.1530801. Epub 2018 Oct 8. PMID: 30296176; PMCID: PMC6335967.

44. Baugh CM, Kroshus E, Kiernan PT, Mendel D, Meehan WP 3rd. Football Players' Perceptions of Future Risk of Concussion and Concussion-Related Health Outcomes. J Neurotrauma. 2017 Feb 15;34(4):790-797. doi: 10.1089/neu.2016.4585. Epub 2016 Sep 16. PMID: 27526721; PMCID: PMC5314987.

45. Purcell LK, Leblanc CM; Canadian Paediatric Society, Healthy Active Living and Sports Medicine Committee, and American Academy of Pediatrics, Council on Sports Medicine and Fitness. Boxing participation by children and adolescents: A joint statement with the American Academy of Pediatrics. Paediatr Child Health. 2012 Jan;17(1):39-40. doi: 10.1093/pch/17.1.39. PMID: 23277756; PMCID: PMC3276529.

46. Concannon LG, Kaufman MS, Herring SA. Counseling athletes on the risk of chronic traumatic encephalopathy. Sports Health. 2014 Sep;6(5):396-401. doi: 10.1177/1941738114530958. PMID: 25177414; PMCID: PMC4137675.

47. Kernick D. Heading the ball in football: what do we tell our patients and why so long to action? Br J Gen Pract. 2019 Jan;69(678):25. doi: 10.3399/bjgp19X700493. PMID: 30591602; PMCID: PMC6301370.

48. Bunc G, Ravnik J, Velnar T. May Heading in Soccer Result in Traumatic Brain Injury? A Review of Literature. Med Arch. 2017 Oct;71(5):356-359. doi: 10.5455/medarh.2017.71.356-359. PMID: 29284906; PMCID: PMC5723188.

49. Lundberg GD, Metzner D. How to Rescue American Football. Cureus. 2016 Apr 28;8(4):e592. doi: 10.7759/cureus.592. PMID: 27284499; PMCID: PMC4889450.

50. Sone JY, Kondziolka D, Huang JH, Samadani U. Helmet efficacy against concussion and traumatic brain injury: a review. J Neurosurg. 2017 Mar;126(3):768-781. doi: 10.3171/2016.2.JNS151972. Epub 2016 May 27. PMID: 27231972. 